\title{
La experiencia fílmica: algunas cuestiones para la reflexión
}

\section{Francesco Casetti}

\author{
(Traducción de Miguel A. Pérez-Gómez) \\ http://dx.doi.org/10.12795/AdMIRA.2009.01.01
}

\section{El cine y la cuestión de la experiencia}

Entre las diversas formas de aproximarse al cine, puede ser útil considerar la manera en que este ofrece al espectador una experiencia muy concreta, hay que tener en cuenta la experiencia filmica ${ }^{l}$. Por lo general entendemos por experiencia la posibilidad de percibir una realidad en primera persona y desde un primer momento ("hacer experiencia”), por otro lado la adquisición de un conocimiento y de una competencia que permiten afrontar la realidad y darle un sentido ("tener experiencia" $)^{2}$. Por analogía, podemos definir la experiencia fílmica como una modalidad particular con la que el cine como institución hace disfrutar de una película al espectador, sea lo que eso signifique, junto a esta modalidad con la que esta institución permite a este espectador reelaborar ese disfrute en un saber y en un saber hacer, que este pone de manifiesto, ya sea reflexivamente, el acto del espectador esta consumando, o de manera proyectada, su relación consigo mismo y el mundo. Así pues, en una primerísima instancia, la experiencia fílmica es una forma de ver que desafía lo obvio de una actividad escópica y que lleva - o puede llevar- al espectador a saber-ver y ser capaz de ver una película tal cual o la realidad a la que esta hace referencia.

\footnotetext{
** Este paper refleja el trabajo del seminario Experience an Reflexivity que tuvo lugar en Yale en el Spring Semester 2007. Estoy agradecido a mis estudiantes por la pasión y la inteligencia con la que han contribuido al trabajo del seminario, y a los que dedico este trabajo.

${ }^{1}$ El concepto de "experiencia fílmica" ha sido elaborado en primera instancia en el cuadro de la filmología, que lo ha transferido a las modalidades de la percepción de las imágenes en movimiento (cfr. en particular la gran síntesis de la investigación filológica propuesta por Dario Romano, L'Esperienza cinematográfica, Firenze, Ed. Universitaria - G. Barbera, 1965). A partir de los años 90 el termino entró en el debate teórico, o como aplicación al cine de la reflexión fenomenológica (Vivian Sobhack, Address of the Eye; a phenomenology of film experience. Princeton university Press, 1992), o como persecución de la reflexión benjaminiana (Miriam Hansen, "Benjamin, cinema and Experience; «The Blue Flower in the Land of Technology»”, in New German Critique, 40 (Winter 1987), pp. 179-224).

${ }^{2}$ Para una definición de la experiencia, para más información ver Paolo Jedlowski, Il sapere dell'esperienza, Milano, Il Saggiatore, 1994 y Martin Jay, "Songs of Experience", in Cultural Semantics. Keywords of Our Time, Amherst, Univ. of Massachusetts Press, 1998. Jedlowski distingue entre la experiencia como: a. percepción de los objetos; recuerdo a la relación con el mundo que lo rodea ("la experiencia de la vida de ciudad es diferente de aquella de la vida en el campo"); b. ejercicios con los objetos; un "hacer" y un "saber hacer" "aquel medico tiene mucha experiencia"); c. elaboración reflexiva de lo vivido; vivido revisitado ("esta experiencia me ha cambiado profundamente"). Jay distingue entre experiencia como: a. [an] immediate sentient observation, which is generally prior to any reflection on its meaning"; b. [the] acquisition of an insight or a wisdom ("only comes with experience"); c. mediating between abstract concepts and concrete particulars, which is why we can "learn from experience" - p.44. Cruzando las definiciones, me parece que emerge por un lado una experiencia como percepción, tendencialmente más allá de una situación en que el mundo es dado por descontado, por el otro una experiencia como reelaboración de esta percepción, tal como "dar sentido" a todo cuanto es percibido (devolviéndole lo vivido) y de transformarlo en base para un saber y saber hacer (y de un conocimiento y de una competencia).
} 
Existen al menos tres buenos motivos para situar la experiencia fílmica en el centro de interés. El primero de ellos es que el visionado de un film, teniendo en cuenta las distintas formas en las que este ha sido realizado, si por un lado constituye una experiencia personal, por otro incide y reorienta el sentido de nuestra experiencia a nivel general. Basta pensar en la forma en la que el cine intenta hacernos ver de nuevo y de forma reiterativa el habito o la indiferencia con la que nos la habían hecho perder de vista, tal y como había subrayado Béla Balasz ${ }^{3}$ en 1924. O incluso la forma en que a veces nos hace ver las cosas no sólo "de nuevo", pero si "como por primera vez", renovando nuestra relación con el mundo ${ }^{4}$. O como el cine sabe evidenciar aspectos inéditos, nunca antes focalizados, que nos permiten una verdadera y precisa reinterpretación de la realidad a la luz de todo aquello que aparece en la pantalla ${ }^{5}$. La conclusión es que la visión del día a día se encuentra a menudo siguiendo el ejemplo de la visión fílmica; hasta el punto de convertirse en una visión “cinematográfica", y pedir a lo real que a su vez se convierta un algo "cinematográfico" para poder ser realmente comprendida. El cine es pues el lugar de una experiencia que ha ido cambiando el significado de la experiencia.

El segundo motivo es de naturaleza histórico-cultural. A lo largo del s.XX la experiencia en general ha conocido una profunda crisis: la manera de percibir el mundo y de reelaborar la percepción de este ha encontrado dificultades. Frente a la complejidad de los eventos y a una realidad en continua transformación, si por un lado hoy día parece imposible "tener una experiencia" en la que basarse para encontrar soluciones, por otro lado parece que ha sido imposible "hacer una experiencia" de aquello que realmente estaba sucediendo ${ }^{6}$. En el corazón de estas crisis, el cine, punta de diamante

\footnotetext{
${ }^{3}$ Bela Balázs, Der Sichtbare Mensch oder die Kultur des Films, Wien und Leipzig, Deutsch-Osterreichisches Verlag, 1924 (tr. it. parcial, Tipo e fisionomia, in «Bianco e Nero», 1, 1941, pp. 6-27; e in L'uomo visibile, in Alberto Barbera, Roberto Turigliatto (a cura di), Leggere il cinema, Milano, Mondadori, 1978, pp. 108-110). El tema será retomado por Benjamin a través del concepto de "inconsciente óptico": ver "L'opera d'arte nell'epoca della sua riproducibilità tecnica", in Opere complete di Walter Benjamin. Scritti 1934-1937, VI, Torino, Einaudi, 2004.

${ }^{4}$ Sobre este tema ver el amplio ensayo de Pietro Montani, L'immaginazione narrativa. Il racconto del cinema oltre $i$ confini dello spazio letterario, Milano, Guerini e Associati, 1999. Entre todas las referencias posibles, hay que recordar el ensayo fundamental de Maurice Merleau-Ponty, "Le dout de Cézanne", en Sens et non-sens, Paris, Nagel, 1948 (tr. it. "Il dubbio di Cezanne", in Senso e non senso, Milano, Il Saggiatore, 1967).

${ }^{5}$ La idea de que un texto (y de manera más general un evento) "permitan" una relectura de la realidad viene definida por Michel de Certeau. Me limito a recordar su extraordinaria reseña, en que hablando de Playtime de Tati, dice:"Ainsi, au sortir de Play-Time, le spectateur se met-il à remarquer l'humour des rues, comme s'il avait leregard de Tati. Le film a rendu possible une observation humoristique qui, sans lui, ne se serait pas produite. Il en va de même pour la lecture d'un poème, la rencontre de quelqu'un, le remuement d'un groupe. Si leregistre de la perception ou de la compréhension s'en trouve modifié, c'est que l'événement a rendu possible et, en un sens très réel, a permis cet autre type de rapport au monde". Michel de Certeau, La faiblesse de croire, Paris, Seuil, 1987, p.210. Más adelante en el parrafo 4, retomaré este tema hablando de la capacidad del cine de reconfigurar el mundo.

${ }^{6} \mathrm{Cfr}$. la dialéctica entre Erfahrung y Erlebnis en Walter Benjamin, sobretodo en ensayos como Erfahrung und Armut, in Gesammelte Schriften, , v. II, t. 1, p. 219, Frankfurt a M., 1972 (tr. it. Esperienza e povertà, en Aa.Vv., Critica e storia, a cura di F. Rella, Venezia, 1980, p. 208, aparecida en Metaphorein,1978, n. 3, (marzo-junio 1978), p. 16.), o “Leskov.
} 
de una serie de medios en vías de afirmarse, ha propuesto de manera paradójica una reactivación de la posibilidad de experiencia: cuando se ve una película, se percibe una realidad de una manera particularmente intensa y se construye una vivencia particularmente eficaz a la hora de proporcionar indicaciones de sentido y reglas de acción. De todas maneras esta propuesta está todavía lejana de la representación de una "restauración" de la experiencia previa. Un poco porque esta creaba un espacio para muchos de los elementos que residían en la raíz de dicha crisis: pensemos también en como el visionado de películas activa lo necesario en la percepción de los acontecimientos, típica de la modernidad, lo que hace difícil conciliar en una verdadera "vivencia" en la medida de lo que percibimos ${ }^{7}$. Un poco porque esta propuesta introducía a su vez algunos elementos "destructivos": solo hay que pensar en cómo la visión fílmica va ligada muy estrechamente a una tecnología, que no solo hace de intermediaria entre el observador y lo observado, sino que por añadidura se impone como una condición esencial para que cualquier cosa pueda ser vista, y consecuentemente contribuye a alejar la realidad de nuestro horizonte inmediato ${ }^{8}$. La conclusión es que aquello que podría parecer un antídoto, se ha revelado en la mayoría de ocasiones como un agravante. O más bien, algo que ha llevado a reflexionar y redefinir lo que es la experiencia en sí misma.

La tercera razón tiene que ver con el momento que estamos viviendo. Con la proliferación de los modos en que se puede disfrutar de una película y el final de la centralidad de la visionado en la sala de exhibición, la experiencia fílmica por un ladoha ampliado sus fronteras, adquiriendo nuevas formas, por otro lado también se ha disuelto en una experiencia mediática genérica, perdiendo su propia especificidad ${ }^{9}$ ¿ ¿En qué medida ver una película en el ordenador o en el teléfono móvil es todavía una experiencia fílmica? ¿Por el contrario en qué medida es una experiencia nueva, marcada por una discontinuidad con respecto al pasado, y emparentada con otras formas de

Il narratore", originariamente aparecido en «Orient und Occident» nell'ottobre 1936, tambien "Il narratore", en W. Benjamin, Angelus Novus. Saggi e frammenti, Torino, Einaudi, 1962, pp. 235-36.

${ }^{7}$ Recuerdo a propósito de esto la fulminante observación de Walter Benjamin en "Su qualche motivo in Baudelaire": "Así la técnica sanciona los sentidos humanos a un complejo entrenamiento. Llega el día en que el film se corresponde con una nueva y urgente necesidad de estimulos. En los films la percepción a saltos se afirma como un principio formal. Esto que determina el ritmo de la producción en cadena, condiciona, en el film, el ritmo de la recepción”, en Angelus Novus, Torino, Einaudi, 1962, p. 107.

${ }^{8}$ De nuevo Benjamin: " la vista sobre la realidad inmediata se ha convertido en una quimera en el país de la técnica", L'oeuvre d'art à l'époque de sa reproduction mécanisée in «Zeischrift für Sozialforschung», I, 1936, ora Das Kunstwerk im Zeitalter seiner technischen Reproduzierbarkeit in Gesammelte Schriften, VII/1, Frankfurt am Main, Suhrkamp Verlag, 1972-1989 (tr. it. L'opera d'arte nell'epoca della sua riproducibilità tecnica, en Opere complete di Walter Benjamin. Scritti 1934-1937, VI, Torino, Einaudi, 2004, p. 293). Sobre este tema ver también: Hansen, "Benjamin, Cinema and Experience", cit.

${ }^{9}$ Sobre la experiencia medial, puede ser útil retomar las ideas de "interacción mediata" o de "cuasi-interacción mediata" (que se afianzan en la interacción cara a cara) desarrlladas por da John B. Thompson, The Media and Modernity, Cambridge: Polity Press, 1995 (tr. it. Mezzi di comunicazione e modernità, Bologna, Il Mulino, 1998, p. 121 y siguientes.). 
visionado? Pero incluso, si se trata de una experiencia nueva, $\Varangle$ a través de que vías se puede eventualmente volver a ser una "visión fílmica"?. El visionado de una película, una vez que pareció caracterizarse por una serie de rasgos precisos y estables, hoy en día tiende a tener unos márgenes mucho más difusos: sobre todo cuando se realiza a través de nuevos dispositivos y en nuevos lugares de visionado, por un lado su identidad tiende a desaparecer, pero por otro, parece renovarse y encontrar una nueva identidad. Preguntarse sobre la experiencia fílmica puede ayudar a buscar mejor entre los pliegues que surgen tras las actuales transformaciones en los medios de comunicación (también en el ámbito de las artes), para entender si estamos al final de la historia o en otra fase de un viaje ya demasiado largo: en resumen, para entender hasta donde hemos llegado y hacia donde nos estamos dirigiendo ${ }^{10}$.

A partir de estas tres razones, y de otras que pueden ser igualmente expuestas, creo que se abre la posibilidad de situar la experiencia fílmica en el centro de dicho interés. Particularmente, creo que legítimamente se puede cuestionar cuales son los elementos y las dinámicas que los caracterizan; en qué modo han contribuido en la redefinición de la experiencia moderna; las diferentes formas que esta ha tomado, incluso compitiendo entre ellas, y de cómo esta, a su vez, ha evolucionado, hasta la situación actual; como un espacio que aún posee, y, por último, el ulterior cambio del horizonte de experiencia que hoy estamos experimentando se refleja en la experiencia medial, aunque también se encuentre en su sustento.

\section{La experiencia fílmica y los film studies}

Antes de entrar en el fondo de la cuestión, es conveniente vincular mejor la reflexión sobre la experiencia fílmica al contexto de los film studies.

Lo primero es que son varios los aspectos de la experiencia fílmica que constituyen un objeto habitual de investigación. Pienso por ejemplo en las investigaciones de psicología experimental desarrollándose en el contexto de la filmología - entre otras la primera aproximación que hace surgir el concepto de "experiencia fílmica"11. También pienso en la semio-pragmatica, y en su

\footnotetext{
${ }^{10}$ Sobre este tema ver una primera exploración italiana en Francesco Casetti, Mariagrazia Fanchi (editada por), Terre incognite. Lo spettatore italiano e le nuove forme dell'esperienza di visione del film, Roma, Carocci, 2006. También ver Barbara Klinger, Beyond the Multiplex. Cinema, New Technologies, and the Home, BerkeleyLos Angeles-London, California University Press, 2006

${ }^{11}$ Ver la amplia síntesis de esta investigación realizada por Dario Romano, L'esperienza cinematografica, cit.
} 
descripción de los distintos contextos institucionales en los cuales un film puede ser localizado ${ }^{12}$. Y pienso, en definitiva, en la cantidad de temas estudiados sobre el tema del spectatorship, desde el rol del aparato al posicionamiento del espectador, de las formas de consumo a las nuevas modalidades de visionado relacionadas con la modernidad y la post-modernidad. Por lo tanto, no se trata de abrir una puerta en un terreno totalmente nuevo. Sin embargo, la investigación sobre la experiencia fílmica puede introducir una pequeña inflexión con respecto a una tradición consolidada.

En primer lugar estudiar la experiencia fílmica implica cuestionarse el modo en el que el espectador está viendo una película, por un lado, teniendo en cuenta la situación en la que este se encuentra, y por otro, teniendo en cuenta el modo de vida de una sociedad. Por lo tanto, no está solo en juego el sentido de un texto, ya sea por sus efectos ideológicos y sociales, en el comportamiento con respecto al consumo, o en un contexto más amplio como el de las prácticas sociales. Están en juego las condiciones de inteligibilidad de todos los elementos que contribuyen y logran el disfrute de una película. ¿Cuándo podemos decir que estamos viendo una película? ¿De qué modo estamos haciendo este visionado? ¿Y qué significado atribuimos al hecho de verla?

Por supuesto, no se trata de encaminarnos hacia una única respuesta. Como en cualquier experiencia de carácter cultural, también la experiencia fílmica está sujeta a una serie de determinaciones históricas y sociales, que no solo han ido cambiando gradualmente sus connotaciones, sino que también han facilitado la aparición de modelos completamente diferentes aunque a menudo coexistentes. Definir la experiencia fílmica también quiere decir articularla en un plano histórico -, así como en relación con el género, la clase social, la ubicación geográfica, etc.

En segundo lugar, estudiar la experiencia fílmica significa intentar entrelazar mejor evidencias empíricas y los datos textuales. Es más, en esta reconstrucción también se puede utilizar la observación directa de carácter etnográfico, sin embargo no se puede prescindir de la existencia de una serie de discursos de distinta naturaleza, unidos entre sí en una especie de gran "red" que envuelve a la experiencia fílmica y a su vez le da brillo y lustre. Entre los discursos mencionados anteriormente, existen dos que parecen tener una posición preponderante. Por un lado tenemos las "biografías de los espectadores", localizadas dentro de "historias de vida" encomendadas a los

\footnotetext{
${ }^{12}$ Fundamentalmente en este cuadro de trabajo esta Roger Odin. En concreto ver Cinéma et production de sens, Paris, A. Colin, 1990, e De la fiction, Bruxelles, De Boeck Université, 2000 (tr. it. Della finzione, Milano, VeP, 2005).
} 
periódicos o a las narraciones, aunque también a la crítica o consideraciones ensayísticas de carácter subjetivo. Por otro lado tenemos aquellos films que reconfiguran situaciones o modalidades de visionado, y que operan de manera reflexiva sobre las condiciones de la recepción fílmica (tanto de terceras personas como en general). Tanto las biografías proporcionadas por las "valoraciones" (account) que evidencian tanto la modalidad de su realización y como el sentido de la experiencia fílmica, y que por lo tanto hacen surgir la inteligibilidad. En particular, este discurso trabaja en el reconocimiento social e individual de la experiencia fílmica. De hecho nos dice que esta resulta identificable a los ojos quien la logra o de quien quiere llegar a hacerlo, y que aparece legitimada en en el plano del comportamiento colectivo (reconocer implica identificar y autorizar) ${ }^{13}$, ya sea como testigos de una serie de operaciones que la sociedad realiza en este sentido, tanto si se es parte activa de estos procesos (un discurso es siempre una representación aunque también una acción). Bajo este aspecto podemos asegurar que la experiencia fílmica no es realmente tal si no es "legitimada", aunque sea de manera discursiva, son estas "legitimizaciones" las que hacer surgir la "consciencia" individual y social sin la cual no habría una verdadera existencia. En otras palabras, la experiencia fílmica, como cualquier otro tipo de experiencia, no sería tal si no encontrase repercusión dentro de la red de discursos que la rodean: las prácticas discursivas que la utilizan (a partir de aquellas proporcionadas por el mismo espectador y por el propio cine), en el proceso de hacerla reconocible, ponen de manifiesto su efectividad.

Por tanto la reflexión que tiene como sujeto a la experiencia fílmica, si por un lado parece alejarse del texto, por otro parece que se acerca a este. Ante todo, porque estamos siempre hablando de una experiencia por el uso de los textos. Pero también son los textos los que presentan las pruebas y su corroboración.

Es a partir de aquí que se ofrece la posibilidad de una descripción de la experiencia fílmica en sus componentes y en su dinámica.

\section{La experiencia fílmica: rasgos caracterizantes}

Existen al menos cinco rasgos que parecen caracterizar la experiencia fílmica las cuales se han ido perfilando en lo que podemos llamar como periodo del cine clásico:

a) En primer lugar se trata de una experiencia posible gracias a un dispositivo. Me refiero por un lado a la tecnología gracias a la cual se forma sobre la pantalla la imagen que se ofrece a nuestra

${ }^{13}$ El reconocimiento siempre implica sea conocimiento más que una aceptación. 
mirada (y el sonido que llega a nuestro oído), por otro lado, de forma más general, al atrezo que rodea al visionado y lo predisponen a desarrollar su función (desde el sofá al mobiliario). Así pues en el lugar en el que se sitúan es por tanto un ambiente artificial.

b) En segundo lugar se trata de una experiencia que tiene que ver con la imagen (y con el sonido). Estas imágenes son la representación que perfilan un "mundo posible", aquel que sufre una puesta en escena y representado en un film. Este también se refiere al "mundo efectivo", ya sea porque hay una impronta (en cuanto a la imagen fotográfica, que registran aquello que ha sucedido ante la cámara fotográfica), o porque son una copia (en cuanto a las imágenes miméticas, que proponen de nuevo los contornos y las características de las cosas). Esto significa que estas imágenes, por un lado "construyen" un mundo "real" pero por otro lo "recuerdan" y lo "vuelven a proponer". Por lo tanto, son "invenciones" sino también "pistas" y "réplicas" de la realidad (basándonos en la trilogía Peirce pueden ser símbolos, índices o iconos).

A los diferentes estatutos se le une otro, el de la pantalla en el que aparecen: como si fuera un "cuadro" en el cual se distribuyen las formas figurativas, aunque también como una "ventana" abierta de par en par al mundo, o un "espejo" en el que se reflejan y se recomponen las formas de la realidad $^{14}$.

c) En tercer lugar se trata de una experiencia que gira en torno a la presencia de un observador, esto es de un sujeto que es ante todo un sujeto escópico. Es más la experiencia fílmica, dejando de lado el oído, moviliza sobretodo la vista, de forma acentuada (la vista en el cine es "aguda") a la vez que especializada (el sentido de la vista a de poder llegar a sustituir a los otros sentidos, por ejemplo al tacto, construyendo un efecto háptico más allá de lo óptico) ${ }^{15}$.

d) En cuarto lugar, se trata también de una experiencia colectiva, basada en la interacción social, en el que un grupo de individuos, una multitud, se convierte en un núcleo orgánico, un público. Esta constitución del público se hace posible por el hecho de que el comportamiento y el

\footnotetext{
${ }^{14}$ Las metáforas a propósito de la pantalla pueden ser numerosas: pensar por ejemplo en aquello que se considera como la "piel" del cuerpo del mundo que se ofrecen a la vista. Es interesante notar como las diversas metáforas usadas por la pantalla tienen que ver con diferentes formas de aproximación: la "ventana" nos lleva a las teorías del realismo, el "cuadro" a de aproximaciones formalistas, el "espejo" (en el que el sujeto escópico recompone el mundo y se recompone a si mismo como parte del mundo) nos lleva al psicoanálisis, la "piel" nos puede llevar a la idea Merleaupontiana de carne del mundo, etc.

${ }^{15}$ Ante la escicsión de tocar y ver en la modernidad, nos tenemos que remitir a Johnatan Crary, Techniques of the Observer, Cambridge, Mass. - London, MIT Press, 1990, en particular el Cap. 1. Sobre la recomposición entre el ver y el tocar en el acto pictórico encuentro una explendida observación de Aby Warburg: "A mitad entre un imaginario manipulable y la contemplación conceptual que permite probar el objetomanipulandolo que da lugar a un reflejo plástico y pictórico que se conoce como el acto artístico" (Aby Warburg, Introduzione all'Atlante Mnemosyne (1929), in Italo Spinelli, Roberto Venuti (editador), Mnemosyne. L'Atlante della memoria di Aby Warburg, Roma, Artemide, 1998, p. 23).
} 
conocimiento de la audiencia son "compartidos": cada uno responde e los requerimientos de la pantalla en sincronía con los demás.

e) En quinto lugar se trata de una experiencia por la cual el espectador paga dinero: en el cine triunfa la idea de que el visionado de una película (no a partir de ella, pero sin duda a partir de una forma definitiva) va ligado al intercambio monetario (y por supuesto la lógica de lo uno va ligada a la lógico de lo otro) ${ }^{16}$ Esto significa que en el cine se realiza una mercantilización de la experiencia que tiene su peso en el significado mismo de aquello que la experiencia puede ser.

\section{La experiencia fílmica: rituales, visiones, y re-figuración del mundo}

Estos cinco aspectos nos permiten entender bien como la experiencia fílmica está en sintonía con la modernidad. Estos, cuestionan aspectos como la naturalidad, la inmediatez, la subjetividad, la sociabilidad y la gratuidad - precisamente aspectos que la modernidad no da por descontado. A lo largo de este recorrido, la experiencia fílmica es uno de los lugares privilegiados en el cual la experiencia en general ha sido debatida y reformulada.

Pero estos cinco aspectos también nos permiten empezar a definir de manera más sintética la experiencia fílmica, solo en el caso del periodo que conocemos como cine clásico. Es, de hecho, una experiencia en la que una de las partes pone en juego una visión centrada en un sujeto escópico, y el otro pone a un grupo de personas, y por lo tanto de los sujetos sociales.

En cuanto a al segundo aspecto, basta con recordar como el cine da lugar a auténticos ritos colectivos, que tienen su inicio dentro de la sala ${ }^{17}$. Son estos ritos, ligados al hecho de que los espectadores responden de manera uniforme a los requerimientos provenientes de la pantalla, como los fieles en una ceremonia laica o religiosa, que consienten transformar la multitud reunida dentro de la sala en una colectividad, en una audiencia. Así pues en sala cinematográfica un individuo se integra o reintegra en un grupo social, y se convierte en miembro de una comunidad.

Hay que tener en cuenta al menos dos observaciones. Estar en la sala cinematográfica implica una serie de acciones comunes (aunque no necesariamente uniformes), también los conocimientos y creencias compartidas. Precisamente este rito requiere una participación ya sea física o intelectual.

\footnotetext{
${ }^{16}$ George Simmel, Philosophie des Geldes, Berlin, Duncker \& Humblot Verlag, 1900 (tr. it. Filosofia del denaro, Torino, UTET, 1984; Il denaro nella cultura moderna, Roma, Armando, 1998).

${ }^{17}$ Hablando de la experiencia fílmica en cuanto a rito, existe la necesidad de comparar con su opuesto propuesta por Benjamins entre valor cultural y valor exhibidito del cine (cult value y exhibition value): cfr. Walter Beniamjn, L'opera d'arte..., cit., parr. 5 e 6.
} 
Por otro lado estar en el cine constituye un momento en el que interviene algo singular y único (si se está allí por una película en concreto y no por otra), aunque también hace referencia a una serie de comportamientos consolidados (si esta allí como siempre en la sala). El rito es precisamente algo que hace converger la excepcionalidad y la rutina ${ }^{18}$.

En cuanto al primer aspecto, en lo que respecta a la visión, el film aspira a "llenar los ojos" del espectador, a requerirlo sensorialmente. La experiencia fílmica moviliza una intensidad perceptiva que lleva al espectador a "sumergirse" en aquello que está viendo. En este sentido podemos decir que la imagen fílmica, más que un objeto para ser visto, constituye un ambiente de visión. Pero parece que el film también hace otra cosa: este parece querer "devolver" al espectador aquella realidad que en la pantalla no está presente en su apariencia; y parece que lo quiere hacer a través de una ilusión.

No existe ningún tipo de duda que en el cine revisamos el mundo: ya sea aquel efectivo en el cual vivimos, o aquel posible en el cual podríamos vivir. La "restitución" tiene lugar en diferentes planos: las imágenes fílmicas pueden ser vistas como "rasgos" o "improntas" de aquello que ha sucedido ante la cámara; pueden ser vistas como "copias" o "facsímiles" del mundo en el que habitamos; y en definitiva pueden ser vistas como "reconstrucción" o "hipótesis" con respecto a la realidad. La diversidad de estos planos crea una especie de doble situación.

De hecho, por un lado el mundo parece "prolongarse" a partir de la realidad de la pantalla, y por tanto, viene a nuestro encuentro al igual que la experiencia cuotidiana. Por otro lado el mundo parece encontrar un "sustituto" en una serie de signos, de discursos, que lo simulan de una forma lo más perfecta posible - y que simulándolo ofrecen, ya sea una magnificación, una nueva versión, un modelo ideal, etc. Los dos aspectos se sobreponen: el mundo viene a mi encuentro, pero es un sustituto del mundo; tan verdadero que aquel mundo que viene a mi encuentro también puede ser un mundo diferente a aquel en el cual vivo, un mundo reorganizado, un mundo hipotético, un mundo de fantasía, y no obstante aquel mundo que viene a mi encuentro exactamente como hace el mundo en el cual vivo en el momento en el cual lo estoy experimentando.

En este sentido podemos asegurar que las imágenes cinematográficas ratifican el eclipse de lo real, y al mismo tiempo se proponen como remedio a este eclipsis - aunque a través de la ilusión. La

\footnotetext{
${ }^{18}$ Naturalmente sobre este tema hay que ver las reflexiones de Benjamin, L'opera d'arte..., cit., sobre el visionado cinematográfico como shock y como habito.
} 
realidad se aleja de nuestro horizonte de percepción, y a su vez aparece una realidad diferente, pero que tiene todas (o casi todas) las características de la realidad de la cual procede. Mejor todavía: la realidad se aleja, y en su lugar le sucede una representación, que conserva un vinculo con lo representado (es a la vez una huella y una copia), y que a su vez pone de manifiesto los puntos de fuerza y sus posibilidades (las imágenes de la pantalla exalta alguno aspectos de la realidad efectiva, pero que también pone de manifiesto una realidad hipotética). En la sala cinematográfica, el mundo en el que vivimos se disuelve, para reaparecer con sus rasgos esenciales y con todas sus variantes posibles. En una palabra, en el cine lo que tenemos es una pérdida de la realidad y una reconquista en forma de espectáculo.

El dispositivo tecnológico en el que se basa el cine acentúa ambos aspectos. Estos ponen en evidencia la no-naturalidad de la situación en la cual el espectador se encuentra inmerso; y al mismo tiempo le asigna un "efecto de realidad" todavía más fuerte a las imágenes fílmicas. Aunque estos también "segregan" con respecto al mundo exterior, y al mismo tiempo nos ofrece una serie de imágenes que "echan abajo" el horizonte habitual de nuestras observaciones. El cine hace vivir una "experiencia real" particular en la que perdemos el contacto con el mundo, y a su vez reforzamos nuestros vínculos con este.

Así pues, a pesar del dispositivo, el cine le devuelve la corporeidad a lo real aunque también contribuye a suprimirla. Lo hace de forma ilusoria: en la pantalla existe una "casi" realidad. Sin embargo, esta "casi" realidad, al recorrer y reconstruir la realidad efectiva, es capaz de exaltar algunos aspectos. Y todavía más, esta "casi" realidad, en el reconstruir de forma hipotética la realidad efectiva, es capaz de poner de manifiesto la posibilidad intrínseca, la potencialidad, la virtualidad, las continuaciones. Magnificación de lo efectivo y exaltación de lo posible: la restauración de la realidad por parte del cine lleva en sí misma dos aspectos. Aquella que esta restituye es pues, el mundo sustraído más la atención y la imaginación ${ }^{19}$. En este sentido podemos asegurar que en el hecho de volverle a dar corporeidad a la realidad, el cine también le da cuerpo a los "fantasmas" que atraviesan una sociedad, es decir sus obsesiones, sus intereses, sus deseos incluido concretamente aquel fantasma que es la nostalgia de la realidad que estamos perdiendo. O

\footnotetext{
${ }^{19}$ Quizás la película que mejor tematiza esta restitución acompañada de atención e imaginación es Lady in the Window de Fritz Lang, a partir de la estupenda secuencia en la que el profesor observa el retrato de una mujer en una vitrina, cuando en la vitrina aparece el reflejo de la mujer, y a sus espaldas aparece en carne y hueso la mujer a la que estaba observando en un cuadro.
} 
más concretamente, lo que da cuerpo a lo imaginario - aquel imaginario que de acuerdo con Morin que siempre a costa de lo real consiente la aprensión personal ${ }^{20}$.

Este aspecto en concreto nos hace entender de forma ilusoria con la que lo real es restituido al espectador y no necesariamente de manera deficitaria, ni una forma de engaño. Esta también puede convertirse en la ocasión en la que el espectador, recuperando la realidad que le ha sido sustraída, lo rearticula en base a los puntos de atención y de las formas de la imaginación que la película sugiere (si se quiere: según el modo en el que le viene sugerido en el imaginario propuesto en el film). En otras palabras al cine, la realidad ilusoria que aparece en la pantalla puede permitir al espectador reconfigurar el mundo. El deseo de realidad consiente a esta reconfiguración de operar a menudo y más en profundidad. Cuando esto sucede, la experiencia fílmica se hace más plena: la percepción se convierte en algo nuevo desde un principio, de manera que el espectador reelabora un conocimiento y una competencia más allá del sentido común. Cuando la visión fílmica reconfigura el mundo, es entonces cuando reconocemos las cosas ${ }^{21}$.

En este juego de sustracción, restitución y reconfiguración de la realidad, el visionado de una película no opera como una simple "identificación” de lo representado, tal y como podría decirse desde la psicología cognitivista. Esta activa un encuentro entre observador y observado que implica una compenetración silenciosa a lo largo sostenida del deseo de re-examinar el mundo ${ }^{22}$.

Junto a este recorrido se encuentran muchas respuestas en el ambiente cultural que ha visto nacer al cine: el sentimiento de pérdida y de reconquista del mundo, su teatralización y el recurso de la ilusión, etc. Son fenómenos típicos de la segunda mitad del siglo XIX. Sin embargo hay algo más. El cine, implicando las imágenes que reconfiguran el mundo a partir de sus huellas, combina una actitud científica (la reconstrucción de lo invisible) con una actitud mágica (el retorno de lo ausente). E implicando las imágenes que permiten reconfigurar el mundo, esto también tiene algo de ascético, según la visión de Ejzenstejinn ${ }^{23}$, y da lugar a una experiencia en cierto modo "religiosa".

\footnotetext{
${ }^{20}$ Edgar Morin, Le cinéma ou l'homme imaginaire. Essai d'anthropologie sociologique, Paris, Minuit, 1956 (tr. it. Il cinema, o l'uomo immaginario. Saggio di antropologia sociologica; Milano, Feltrinelli, 1982).

${ }^{21}$ Pietro Montani en L'immaginazione narrativa, cit., que explorado espléndidamente este momento.

${ }^{22}$ Importante en este sentido la recuperación de la temática fenomenológica. Ver Vivian Sobchack, The Address of the Eye: a Phenomenology of Film Experience, Princeton, N.J., Princeton University Press, 1992.

${ }_{23}$ El hacer referencia se encuentra en la reflexión sobre el mecanismo del pathos en Sergei M. Ejzenstejn, Neravnodušnaja priroda en Izbrannye proizvedenija v šesti tomach, III, Moskva, Iskusstvo, 1963-1970 (tr. it. La natura non indifferente, in Opere scelte di Sergej M. Ejzenštejn, III/1, Venezia, Marsilio, 1992).
} 
Este esbozo sintético de la experiencia fílmica hace referencia a lo que ha sido el cine en sus primeros cien años de vida. Evidentemente es necesario preguntarse que está cambiando en esta experiencia, ya sea por la llegada de las imágenes electrónicas, o por la multiplicación de pantallas en las cuales podemos ver imágenes en movimiento (solo algunas de estas entran en la definición de lo que solemos conocer como una película) La imagen digital, sobretodo en el punto en que esta se desvía hacia una reelaboración anti-realista del mundo representado, ¿tiene todavía como finalidad una recuperación y una reconfiguración de la realidad? Es la progresiva expansión de imágenes de tipo didáctico-informativas (pienso, por ejemplo, en el navegador de nuestro coches, autentico heredero de los travelogues de los inicios del cine) así como la expansión de imágenes que nos llegan desde las practicas de vigilancia (pienso en la webcam, heredera de las vistas de los hermanos Lumiere) la presencia de las cuales también caracteriza al cine ${ }^{24}$, ¿introducen estas otras dimensiones en la experiencia fílmica tradicional? Por ejemplo, ¿trasladan el juego descrito anteriormente del plano del conocimiento al del control, del poder? ¿Transforman la reconfiguración en cartografía? ¿Garantizan no una restitución pero si una aproximación?

\section{La experiencia fílmica: la definición de la situación}

Para comprender el sentido de la experiencia fílmica es necesario tener en cuenta otros aspectos. He comentado anteriormente la importancia de tener como punto de partida la "consciencia" que existe tanto en el plano individual como en el social. Los sujetos viven una situación concreta; pero además de vivirla, y mientras la viven, estos también la "definen", y a través de este camino reconocen vivir una experiencia y el tipo de experiencia que están viviendo. Pues bien, un modo fundamental de definir la experiencia fílmica parece ser, al menos en el periodo del cine clásico, aquella que hace referencia por un lado el cuadro espacial en la cual esta tiene lugar, y por otro el cuadro mental en el que esta se desarrolla.

La experiencia fílmica reclama una definición de orden espacial: se trata de reconocer en qué ambiente en el que esta se desarrolla y como se distribuyen los diferentes elementos en juego. Lo que aquí emerge es el setting de la visión. El hecho de que el espectador se sienta situado "frente a" la imagen de la pantalla, que el dispositivo asociado este "a sus espaldas" (y ambos hacen que la tecnología los "rodee"), que la realidad a la que la imagen hace mención este por decirlo de alguna

\footnotetext{
${ }^{24}$ Ver en particular por el modo en el que el cine (y el arte contemporáneo) recuperan las practicas de vigilancia, el excelente trabajo de Thomas Y. Levin, Ursula Frohne, Peter Weibel (editoresi), Ctrl (space): rhetorics of surveillance from Bentham to Big Brother, Karlsruhe, ZKM Center for Art and Media - Cambridge, Mass., MIT Press, 2002.
} 
manera "apartada del alcance" del campo de visión, que a diferencia del "más allá de la pantalla" se constituya un verdadero (nuevo) mundo, etc. hay una serie de aspectos no sin importancia. Precisamente estos esbozan la situación física en la que tiene lugar la experiencia, y de forma paralela fijan la experiencia en una situación física concreta. Entonces, reconocer el setting implica

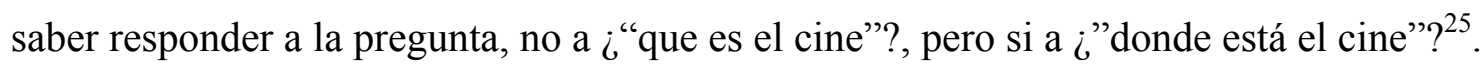

Naturalmente, este "donde" puede cambiar, sobretodo tal y como tiene lugar actualmente. El desarrollo del cine a día de hoy parece vinculado por un lado, al reafirmarse en nuevas instalaciones espaciales (pensemos por ejemplo en el trasvase de la visión fílmica al ámbito domestico, y como este ámbito transforma la relación entre los diferentes elementos), por otro lado la perdida de una vinculación con un espacio concreto (pensemos en como la visión fílmica vía ordenador, y en el modo en que esta "anula" el sentido de lugar) ${ }^{26}$. Definir la experiencia se convierte en algo difícil.

Paralelamente a una definición de tipo espacial, la experiencia fílmica se presta también a una definición que podríamos definir como "mental", que arremete el modo por el cual los sujetos caracterizan de manera global aquello que están viviendo. Aquí, más que un ambiente, se trata de reconocer la circunstancia que se está afrontando, el cuadro de acciones en la cual nos estamos moviendo: en una palabra, el frame en el cual se está trabajando y se acepta obrar. Un frame establece un estado de cosas, los comportamientos adaptados a este, y su posibilidad de evolucionar; reconocer el frame significa entender en qué tipo de contexto esta y asumirlo como cuadro de referencia.

La experiencia fílmica clásica, aquella de la visión en sala, asociaba y sobreponía dos frames: por un lado aquel de un encuentro social, de un gathering, en el que el espectador se encontraba cara a cara con otros espectadores; por otro lado el de una visión propia y auténtica, de cara a la pantalla, en el que el espectador estaba cara a cara con la película. La experiencia fílmica nace de una doble raíz que se fundían entre ellas ${ }^{27}$. A día de hoy no solo esta combinación no parece ser un rasgo necesario; también cambian, junto a los lugares, los frames. Basta pensar, en dos casos opuestos, en

\footnotetext{
${ }^{25}$ Esta línea de investigación - que lleva en si una aproximación fuertemente anti-existencialista - hasido recientemente llevada delante de manera muy persuasiva por Janet Harbord, Film Cultures, London - New Delhi, Sage, 2002. Harbord construye una "genealogía" de los lugares en que se consume cien en la actualidad, partiendo de la contraposición entre nickleodeon, art galleries y cineclubs.

${ }^{26}$ Bajo esta óptica puede ser útil dedicar atención a la presencia del cine en aquellos lugares que Marc Augé llama los no-lugares para ver si estos resemantizan estos espacios. Marc Augé, Nonlieux: introduction à une anthropologie de la surmodernité, Paris, Seuil, 1992 (tr. it. Nonluoghi: introduzione a una antropologia della surmodernità, Milano, Elèuthera, 1993).

27 Para este concepto ver Eric Feldmann, Considérations sur la situation du Spectateur au Cinéma, en «Revue Internationale de Filmologie», 26, 1956.
} 
el visionado de un film de artista en una galería, y en la visión de una película en un avión o en un autobús, y a los cambios que esto comporta sobre la capacidad espectatorial. Aunque en este punto, resulta difícil intentar definir la experiencia.

Queda en cualquier caso el hecho de que la experiencia fílmica se ha prestado durante mucho tiempo a un reconocimiento que partía del ambiente y de las circunstancias en las cuales esta tenía lugar. Este reconocimiento restituye, por decirlo de alguna manera, la "consciencia" inmediata a la experiencia - "consciencia" que abarca el "donde" y el "como" de esta experiencia, un ajuste y un frame. Contemporáneamente, este reconocimiento ha hecho aparecer la experiencia fílmica como una experiencia localizada y limitada.

Para empezar, una experiencia localizada. Un espectador siempre ve una película en un lugar determinado y en un determinado cuadro de acciones. Es, pues, un sujeto que está situado, tanto física como mentalmente. Es en este "espacio" pero también en este "tiempo" de la experiencia fílmica, que el film "viene al encuentro" del espectador: tal vez como un don, o tal vez como una violenta amenaza, o como un enigma, etc. Y es en este "donde" y en este "cuando" que la visión fílmica toma cuerpo: tal vez deteniéndose en el "espectáculo" ofrecido en la pantalla, por otro lado poniendo en juego la realidad que nos rodea, por otra cimentando una retroalimentación productiva entre las dos. Una "geopolítica" de la experiencia fílmica tiene que partir de lo que nos viene dado $^{28}$.

Paralelamente, una experiencia limitada, esto es dotada de confines, tanto físicos como mentales ${ }^{29}$. El visionado de una película tiene sus lugares y sus circunstancias y no se confunden unos con otros. Y estos lugares y circunstancias son marcados necesariamente por unos umbrales. Esto no impide a la experiencia fílmica de agregar otra serie de comportamientos y de acciones: es típico entre los fans, por ejemplo, asociar al visionado de una película una serie de actividades que más que continuar, la integran y la completan. Es así como esto no impide asumir una ejemplaridad de lo que la hace vivir más allá de sus estrechos confines: pensemos en cómo sus modalidades se proyectan a menudo en otras necesidades ("parecía estar en el cine”) y asimilan estas últimas en una visión autentica y propia.

\footnotetext{
${ }^{28}$ Hará falta preguntarse que formas de representación ha elaborado cada cultura a diferencia y contra el modelo mainstream de Hollywood, que significado ha tenido ir al cine en las diferentes culturas - más allá de la experiencia fílmica a la que el mundo occidental nos ha acostumbrado.

${ }^{29}$ Sobre la delimitación de la situación, ver Francesco Casetti, "Communicative Situations: The Cinema and the Television Situation", in «Semiotica», 1/2, 1996, y en Communicative Negotiation in Cinema and Television, Milano, VeP, 2002.
} 


\section{La experiencia fílmica: el rol de las normas}

Para ser reconocida individualmente y socialmente - por otra parte esta no existiría sin este reconocimiento - la experiencia fílmica debe someterse a una serie de reglas que le dan forma, y modelan, esto le permite adquirir tanto el hecho de hacerla reconocible como legitimizarla. Estas reglas le otorgan desde un principio a la visión fílmica muchos niveles: por ejemplo, tiene que ver el hecho de que la imagen adopte "buenos contenidos" o "buenas composiciones"; y que también el disfrute tenga lugar en un "buen ambiente" y se desarrolle con "buenas prácticas"; que los espectadores adopten un "buen comportamiento social"; etc. Estos aspectos esbozan una verdadera “disciplina" en el sentido foucaultiano del término ${ }^{30}$, en cuyo radio de acción parece entrar el cine. Es indudable que esta disciplina apunta a la "subjetivización" de los espectadores y a hacerlos "funcionales" a los diseños sociales. El cine inaugura una experiencia que tiene en si misma algo de "excesivo" (basta pensar en la intensidad de la percepción) y de "liminal" (solo con mencionar el "mundo aparte" que se crea en la sala cinematográfica basta); de ahí deriva la necesidad de tener bajo control todo lo que está de "más" o se "aleja" de los limites “ordinarios". Sin embargo, las reglas no sirven solo para llevar a la "justa” medida la visión fílmica (precisamente para convertirla en una "buena" visión). Esto sirve también sobre todo para obtener un reconocimiento social, esto es hacer que la visión en si misma se convierta en un acto bien identificable (precisamente porque se basa en reglas muy especificas) y aceptado (únicamente para que no esté fuera de la norma). Resumiendo, el cine debe "disciplinar" su forma de ser, no tanto para crear cuerpo y mentes "dóciles" con vistas a una finalidad productiva, sobre todo porque solo a través de una "regulación" este asume una configuración reconocible y reconocida.

Lo "excesivo" y lo "liminal" de la experiencia fílmica no desaparece nunca del todo: esta sigue operando en un segundo plano. De ahí un proceso contrario, que se entreteje con el proceso disciplinar: el espectador pone en marcha una serie de tácticas que le permiten "apropiarse" de los elementos dispuestos (elementos "regulados") para confeccionar una experiencia que sea efectivamente suya. De nuevo, esta "apropiación" funciona a diferentes niveles: del uso de "lecturas desviadas" a la utilización de comportamientos "inconvenientes". Sobre todo desde el plano de la lectura, habitualmente tendemos a hacer interpretaciones "no autorizadas" del film proyectado, sobre el cual, la fantasía del espectador juega un papel muy importante (ya sea por dar cuerpo a la

\footnotetext{
${ }^{30}$ Michel Foucault, Surveiller et punir. Naissance de la prison, Gallimard, Paris, 1975 (tr. it. Sorvegliare e punire, Torino, Einaudi, 1976).
} 
propia obsesión, o por encontrar respuestas a los dilemas de la vida ${ }^{31}$. Resumiendo, si es verdad que el espectador hace frente a una disciplina, es también verdad que en el cuadro de la experiencia fílmica, la practica en si misma se puede considerar como poaching (por usar el concepto adelantado por de Certeau $)^{32}$.

\section{Formas de la experiencia fílmica: algunos apuntes temáticos e históricos}

En el momento en que viene definida, así como en el momento en que viene regulada, la experiencia asume una forma precisa. Es precisamente esta forma suya (o mejor todavía, en sus formas, en plural) que esta viene reconocida como tal, esto es, identificada e instituida tanto individualmente como socialmente.

La presencia de una forma es importante. De hecho por un lado esta nos recuerda que el cine ha sido capaz de elaborar no solo formas de representación, ni tan solo formas de percepción, si no también aquellas que podemos denominar como formas de vida. Por otro lado se abre un campo de estudio concreto: la forma de la experiencia fílmica nos dice como el cine ha sido visto y vivido en diferentes fases; o también, esa "consciencia" de su presencia que poco a poco ha ido obteniendo. Partiendo de este último punto, intentare recordar, de manera muy sintética, algunos pasajes relevantes.

a. (modernidad y popularidad) Desde el principio el cine se caracteriza como un fenómeno moderno a la vez que popular. Por un lado la experiencia fílmica parece incluir todos los rasgos de su tiempo ${ }^{33}$ : esta se puede comparar con la necesidad de economizar, con el gusto por la velocidad, con la progresiva mecanización de la vida, con el relevo cada vez más veloz de fenómenos contingentes y fugaces, con un pensamiento que asume las formas de un flujo incontrolado, etc., como bien evidencian la gran cantidad de ensayos aparecidos en las dos primeras décadas del siglo

\footnotetext{
${ }^{31}$ Un ejemplo de contraste entre interpretación autorizada y no autorizada es La ventana indiscreta de Alfred Hitchcock gran metáfora de la visión fílmica: el detective Doyle (portador por excelencia de una "lectura" regulada de la ley) que quiere aferrarse a aquello que es cierto mientras que el reportero Jeff (periodista fascinado con la historia) hace su propia interpretación aparte de lo licito. No hace falta decir que Jeff tendrá razón...

${ }^{32}$ Michel de Certeau, L'invention du quotidien, 2 voll., Paris, Gallimard, 1990-1994 (tr. it. L'invenzione del quotidiano, Roma, Edizioni Lavoro, 2001).

${ }^{33}$ Bajo este aspecto el cine ofrece una experiencia "de la" modernidad, por el momento gracias a esto se esperan nuevos parámetros típicos del tiempo; pero el cine ofrece una experiencia "en la" modernidad en el momento en el que el uso del tiempo ofrece un contexto adecuado para obtener su propia potencialidad.
} 
$\mathrm{XX}^{34}$. Por otro lado la experiencia fílmica se presenta también como una experiencia "popular": esta implica a una franja amplia y transversal de población, con un lenguaje accesible para todos, y proponiendo valores de carácter universal ${ }^{35}$. Aunque en este caso el cine responde a una exigencia de su tiempo, aquella de una gran "democracia artística",36. Es importante subrayar que la modernidad y la popularidad en el cine asumen una apariencia particular, aquella que dan los mismos films, pero se trata de una apariencia que se impone con una amplia difusión, y que por esto mismo tiende a ser canónica ${ }^{37}$. (la velocidad, la mecanización, el flujo, etc., transforman la idea que de estas se ha proporcionado a través del cine). Esto significa que en el cine la modernidad finaliza en el momento que encuentra su faceta, por llamarla de alguna manera, más popular; y paralelamente a la popularidad que asume el cine la dimensión moderna que esta le da - reelaborada y propuesta por un medio de masas, de hecho se convierte en una popularidad "de masas" y "mediática".

Esta orientación que adopta la experiencia fílmica con respecto a la modernidad y la popularidad, hace que esta, en los dos primeras décadas del s. XX, sea interesante, sobre todo, por su capacidad de ofrecer una nueva gama de sensaciones y de construir una nueva categoría de colectividad. Eso que la visión fílmica reconfigura son precisamente estos dos aspectos, que encuentran su punto de convergencia en un espectador que redescubre el propio cuerpo como cuerpo sensible a la vez que colectivo.

Es necesario releer a un autor como Canudo bajo esta óptica. Por el hecho de que muchos de sus escritos están constituidos por críticas cinematográficas, el autor está atento, por encima de otras cosas, a la forma en que el cine activa una nueva sensibilidad y nuevas vinculaciones sociales ${ }^{38}$. Desde esas páginas emerge con claridad como en esta primera fase de la experiencia fílmica un

\footnotetext{
${ }^{34}$ Para Italia bastara con pensar en Giovanni Papini, La filosofia del cinematografo, in «La Stampa», Milano, XLI, 18 maggio 1907, y en Enrico Thovez, L'arte di celluloide, in «La Stampa», XLII, 209, Torino, 29 luglio 1908.

${ }^{35}$ Ver el importante texto de Louis Delluc, Le cinéma, art populaire (1921), también en Ecrits cinématographiques. Le cinéma au quotidien, II/2, Paris, Cinémathèque Française, 1990, pp. 279-288.

${ }^{36}$ Concepto avanzado por Eugenio Giovannetti, Il cinema e le arti meccaniche, Palermo, Sandron, 1930.

37 Para este proceso, cfr. el concepto de "puesta en forma negociada" avanzado por Francesco Casetti, L'occhio del Novecento. Cinema, esperienza, modernità, Milano, Bompiani, 2005.

${ }^{38}$ Ver en particular Ricciotto Canudo, Lettere d'arte. Trionfo del cinematografo, in «Nuovo Giornale», 25 noviembre 1908, también en «Filmcritica», XXVIII, 278, noviembre 1977, pp. 296-302
} 
espectador es tal no tanto porque "ve una película", sino como por aquello que "siente" y “experimenta" a través del visionado de una película en el plano estético, psicológico y social ${ }^{39}$.

b. (La institucionalización) A partir de la primera guerra mundial, lo que empieza a surgir es el trabajo de "regulación" tanto de la forma de representación fílmica como en la conducta espectatorial. El cine debe responder a las necesidades de una moral, de una etiqueta, de una higiene: solo en estas condiciones se puede llegar a una "buena" experiencia". Esta "regulación" acompaña y articula un proceso más general: el cine se "institucionaliza", y esto estabiliza sus modos de ser y de hacer, mientras tanto esta se convierte en una "institución social", y esto es algo reconocible y reconocido ${ }^{40}$.

Dos observaciones. En primer lugar, para entender este proceso de institucionalización a nivel de experiencia, puede ser interesante hacer un seguimiento sobre el difícil equilibrio entre cinéfilo y cinéfobo (reedición del antiguo conflicto entre iconoclastas e iconófilos) que caracteriza el debate sobre el cine sobre todo en la segunda década del siglo ${ }^{41}$. De hecho ambos frentes, pero desde dos perspectivas opuestas, evocan un "modelo" de cine - para unos cumplido, y para los otros traicionado - capaces ambos de legitimar su presencia. La segunda observación, las posibles conexiones entre el proceso de institucionalización que nace de dos necesidades, aquellas de carácter narrativo (manifestado sobre todo por el público, y que se encuentra en la base del progresivo aumento del largometraje de ficción“) y el de carácter artístico (manifestado a nivel intelectual, y que se encuentra en la base de la progresiva "santificación" de la obra fílmica).

c. (la attendance) La institucionalización del cine nos lleva hacia un modelo de experiencia fílmica que podemos llamar como attendance. Eso se caracteriza por la relevancia que tiene el objeto de la visión con respecto al ambiente en que tiene lugar el visionado o con respecto al trasfondo en el cual se proyecta. El espectador busca una vinculación con el film, más que con el público es con este en sala; trabaja sobre una forma de ver, más que sobre un sentir genérico; y acompaña su propia forma de ver, más que con un comportamiento físico (que no desaparece), con la continua proyección e identificación mental con aquello que es representado ${ }^{42}$. Además actúa una

\footnotetext{
${ }^{39}$ Un grupo de películas de Uncle Josh at the Moving Picture Show (E. Porter, Usa, 1902) hasta Mabel's Dramatic Career (Sennet 1913) o una A Movie Star (sup. Sennet, 1913) nos ilustran con gran claridad este nodo central de la experiencia fílmica.

${ }^{40}$ No existe ningún caso en el que Noel Burch llame "forma institucional de representación" aquello que se denomina como cine clásico o cine mainstream o cine del absorbimiento diegético.

${ }^{41}$ Un buen indicador de este debate es la polémica que en Francia opone Pierre Souday e Emile Vuillermoz: cfr. P. M. Heu, Le Temps du cinéma. Émile Vuillermoz pére de la critique cinématographique, Paris, L'Harmattan, 2003.

${ }^{42}$ Se trata tal como se ha apuntado de una doble identificación: por un lado los personajes y los objetos de la.visión del otro la mirada dentro del radio de la cual se hallan. Cfr. Christian Metz, Le signifiant imaginaire. Psychanalyse et
} 
fuerte regulación de los modos de ver: el cuerpo del espectador es progresivamente limitado en sus comportamientos; y si la actividad escópica es exaltada, esta encuentra también un objeto en el que la visibilidad esta reglada (crece la "disciplina del ojo", ya sea en el aspecto del contenido - el código Hays - o en el de la sintaxis narrativa y compositiva - la elaboración de una "gramática fílmica", a la que contribuye textos teóricos como los de Pudovkin, Arnheim, Spottiswoode,etc.) ${ }^{43}$. La experiencia fílmica consiste sobre todo en un film y asociarse a su desarrollo ${ }^{44}$. Eso que esta reconfiguración es todavía un mundo, como un espectáculo gigantesco: en el cine la realidad que nos rodea, nuestros sueños, nuestro cuerpo, revelan el aspecto seductor de estos como objetos a la vista $^{45}$.

d. (crisis de la attendance) El modelo de attendance entra en crisis, en el plano general antes que en el práctico, a partir de la segunda postguerra. La creciente consciencia del film como acto político (relanzada por el Neorealismo italiano) a la vez que como acto creativo de un autor (reivindicada por el "manifiesto" de Astruc que equipara la cámara con una pluma con la que el director escribe sus obras), hacen que el espectador no sea llamado únicamente a "asistir" a un film: este debe "responder" a la película, a la vez que "corresponder" a su autor. En la experiencia fílmica entra en juego por un lado los efectos perlocutivos del film, y eso es "hacer" o puede "para hacer" al espectador, por otro la posibilidad de un "dialogo" con el director, que crea una comunidad "exclusiva" de la que hacen formar parte al autor y sus espectadores antes que los espectadores con el resto de la ciudadanía.

e. (sobre la performance). A partir de los años 80. El cambio se hace todavía más evidente. Dos parecen ser los motivos que llevan a este cambio. Por un lado está el nacimiento de una

cinéma, Paris, Union générale d'éditions, 1977 (tr. it. Cinema e psicanalisi. Il significante immaginario, Venezia, Marsilio, 1989).

${ }^{43}$ Vsevelod I. Pudovkin, Kinorežissër i kinomaterial, Moskva, Kinopeciat, 1926; y Kinoscenari, Moskva, Kinopeciat, 1926 (tr. it. en Film e fonofilm. Il soggetto, la direzione artistica, l'attore, il film sonoro, Roma, Le Edizioni d'Italia, 1935; también en La settima arte, Roma, Editori Riuniti, 1961); R. Arnheim, Film als Kunst, Berlin, Ernst Rowohlt Verlag, 1932 (tr. it. parcial Film come arte, Milano, Il Saggiatore, 1960); R. Spottiswoode, Grammar of the Film, An Analysis of Film Technique, London, Faber and Faber, 1935 (trad. it. parcial, Grammatica del film, in «Bianco e Nero», (II), 6, 1938).

${ }^{44}$ En el attendance tenemos la conversión de un sujeto pragmático en un sujeto cognitivo: el espectador pasa de una visión a través de la cual "pone a prueba" al mundo y a sí mismo (cfr. la noción de visión fílmica como un test en Benjamin, en La obra de arte..., cit.) y una visión que recorre un mundo predispuesto por el, creyéndose que forma parte de él. Así pues pasa del miedo al placer, de la curiosidad al estupor; de una actitud de conquista a un comportamiento contemplativo; lo que para el mundo representado quiere decir pasar de un rol de amenaza de domar aquello que acoge. El pasaje de un comportamiento a otro es magníficamente representado por Buster Keaton en Sherlock Junior (la bola numero 13): este pasa de la desorientación inicial, cuando entra en la pantalla se encuentra en un mundo que lo sorprende de manera continuada, a la adecuación sucesiva, cuando siempre dentro de la pantalla se convierte en un personaje de la historia y guía el desarrollo de la misma.

${ }^{45}$ Hago aquí una referencia directa al concepto de "to-be-looked-at-ness" elaborado por Laura Mulvey, Visual and other pleasures, Bloomington, Indiana University Press, En general podemo decir que en muchos aspectos la teoría de la "posición espectatorial"(subject position) de los años 70 y 80, es - con retraso, cuando el modelo habrá entrado en crisis- una teoría del attendance. 
necesidad de racionalidad por parte del sujeto social: la propia identidad depende de la relación con los otros. El cine ofrece una representación del mundo, pero menos espacio para el cambio (el encuentro social antes y después de la proyección, el dialogo virtual con el autor, los discursos en los círculos cinéfilos, etc.). Sin embargo, otros medios responden mejor a estas demandas; si el cine quiere seguir teniendo un papel central, debe recuperar estas prácticas para sí mismo ${ }^{46}$. Por otro lado tenemos el surgimiento de una necesidad de expresividad por parte del sujeto social: la propia identidad depende de cómo se introduce en escena, el cine ofrece la ocasión de asistir a un espectáculo, pero no de ser el protagonista al menos de forma virtual. Otros medios parecen hacer esto mejor; el cine debe actualizarse ${ }^{47}$.

En este trayecto hacia las nuevas exigencias, el cine trabaja sobre métodos tradicionales propios, con la posibilidad de un desarrollo intrínseco: pienso en el consumo de culto (los cineclubs, las salas especializadas) con la comunidad de fans que interactúan entre ellos y la pantalla, a menudo criticando en la sala aquello que están viendo; también en el consumo en "salas pequeñas" o en las de "ensayo" en la que el espectador se siente "en casa". Aunque también activa nuevas formas de disfrute nunca antes experimentadas: el consumo domestico, primeramente a través del VHS y más adelante mediante el DVD; el consumo televisivo fragmentado en canales temáticos, etc. Todo va hacia la experiencia personalizada, en el sentido de que es un disfrute que responde a unas necesidades específicas, en vez de indistintas, pero también esta tiene lugar en espacios privados, en vez de públicos, por tanto una experiencia que ve al consumidor recupera una posición central como sujeto (social, o quizás trans-social).

Dos apuntes. En primer lugar esta experiencia personalizada reinterpreta a fondo el desplazamiento que tiene lugar en la cultura popular en el cuadro de lo post-moderno. Se trata de una cultura que exalta la participación en una red de relaciones interpersonales antes que la pertenencia a un colectivo de individuos, en los que se privilegia la proyección de uno mismo al exterior a través de diversos canales de comunicación, antes que la absorción dentro de sí mismo de representaciones ofrecidas a algunas grandes agencias de comunicación, luego, nunca más una cultura será de masas y mediática, pero si una cultura post-masiva e hiper-mediática. En segundo lugar esta experiencia personalizada marca el fin de un espectador que simplemente disfruta de un espectáculo, y el nacimiento de un espectador que participa en aquello que está a punto de consumir: este está

\footnotetext{
${ }^{46}$ La televisión es más capaz que el cine de adaptarse a esa exigencia emergente: dispensar programas (paleo-tv) se convierte en los años 80 en un medio de contacto con los telespectadores, gracias a la línea de retorno del teléfono, la inclusión en los programas de cualquier tipo de personas,etc. (neo-tv)

${ }^{47}$ En este caso el medio más rápido de responder a esta necesidad de expresividad sea quizás la moda: el cine se limita a proporcionar identificaciones simbólicas, esto es un atuendo puramente mental.
} 
llamado no solo a ver, sino que también a hacer ( $\sin$ nada más que hacer, se le permite ver) ${ }^{48}$. Para esto me gustaría caracterizar este tipo de experiencia como performance.

Los niveles de performance en los que el espectador se involucra son, por otro lado, varios. Existe, como he mencionado, un hacer relacional y expresivo: la experiencia fílmica es ya valorada desde su construcción de redes sociales y de la manifestación de sí mismo. Existe un hacer cognitivo, vinculado a la activación de diferentes formas de interpretación, de incorporación y de uso de los recursos simbólicos propuestos por la película. También existe un hacer práctico, vinculado a los comportamientos relacionados con el proceso de consumo, y que va del hecho de efectuar determinados recorridos espacio-temporales para llegar al lugar de disfrute hasta el hecho de intervenir en la tecnología del visionado para poder activar la distracción y componer el "menú" de aquello que se quiere ver-

f. (windows) Sin embargo, estos comportamientos, que ven al espectador como un agente activo, no tienen sentido a menos que se vuelva a los nuevos cuadros en los que tiene lugar el disfrute. Las películas se ven en un amplio número de circunstancias, en diversos y numerosos ambientes y a través de cuantiosos medios. Se añaden una amplia gama de productos, diversificados por soporte, por funciones y por formato. Es oportuno en este sentido identificar las diversas windows que permiten la experiencia fílmica, caracterizándola en términos espacio-temporales, en términos tecnológicos, en términos sociales, y con respecto al tipo de producto implicado. Es dentro de este cuadro que se puede reconstruir el papel y el trayecto del espectador, y luego definir en última instancia el tipo de experiencia que estos encuentran.

Podemos concluir nuestro pequeño recorrido señalando una discontinuidad. Desde hace tiempo la experiencia fílmica era inmediatamente reconocible gracias a un setting y a un frame, esto es, a la situación espacial en que esta tenía lugar y al cuadro mental por el que podía ser adquirida: hoy necesita ser definida en relación con aquello que hemos definido como window. Esto comporta como mínimo tres cosas: debilitar la determinación espacial (la experiencia fílmica ya no depende del todo de un lugar); introducir una determinación medial (la experiencia fílmica estaba relacionada con el medio cine; hoy puede reconsiderarse a través de diversos medios); reformular el frame (no tenemos nada que hacer con el añadido de un gathering, de un encuentro social, y de un visionado). Existe todavía un elemento que persiste, es la presencia de los procesos disciplinarios, en continua dialéctica con la creatividad de los sujetos, con su propia anti-disciplina (hemos

\footnotetext{
${ }^{48}$ Régis Debray, tratando el tema de la "videosfera", habla abiertamente de "fin del espectáculo", asociándola también una debilitación general del papel de la vista. Crf. Vie et mort de l'image. Une histoire du regard en Occident, Paris, Gallimard, 1992 (tr. it. Vita e morte dell'immagine, Milano, Il Castoro, 1999, p. 228 e segg.).
} 
hablado de poaching). Esta "regulación" de las windows sirve tanto para normativizar los comportamientos espectatoriales y los contenidos de la visión, como para hacer reconocibles y reconocidas las nuevas modalidades de la visión. Bajo este aspecto quizás podemos decir que será el juego de disciplina y antidisciplina lo que al fin proporcionará la definición de las nuevas formas de experiencia fílmica - así como suministrar la respuesta a la pregunta, radical, si la experiencia fílmica sobrevivirá en estas condiciones cambiantes, o si se agotará convirtiéndose en un fenómeno arqueológico. 